\title{
Power Quality Analysis for Modular Structured Multilevel Inverter with Bipolar Variable Amplitude Multicarrier Pulse Width Modulation Techniques
}

\author{
Venkatasubramanian D. \\ Ph.D Research Scholar \\ Department of Instrumentation \\ Engineering, Annamalai \\ University, \\ Tamilnadu-608002, India.
}

\author{
Natarajan S.P. \\ Professor and Head \\ Department of Instrumentation \\ Engineering, Annamalai \\ University, \\ Tamilnadu-608002, India.
}

\author{
Shanthi B. \\ Professor \\ Department of Instrumentation \\ Engineering, Annamalai \\ University, \\ Tamilnadu-608002, India.
}

\begin{abstract}
MultiLevel Inverter (MLI) is used in applications that need high voltage and high current especially for Flexible AC Transmission System (FACTS) controllers. The topologies of multilevel inverter have several advantages such as lower Total Harmonic Distortion (THD), lower ElectroMagnetic Interference (EMI) generation and high output voltage. The main feature of Modular Structured Multilevel Inverter (MSMI) is the ability to reduce the voltage stress on each power device due to the utilization of multilevel on the DC bus. The advent of multilevel inverter topologies has caused variety of pulse width modulation strategies. In this paper, multi carrier pulse width modulation techniques are proposed which can minimize the total harmonic distortion and enhance the output voltage for five level cascaded MLI. Methodologies adopting the Constant Switching Frequency (CSF) and Control Freedom Degree (CFD) concepts are proposed in this paper. To validate the developed technique, simulations are carried out through MATLAB/SIMULINK for the chosen five level inverter. Harmonic analysis and evaluation of performance measures for various modulation indices have been carried out. The above methodologies are divided into two types of techniques like (I) phase disposition pulse width modulation which minimizes total harmonic distortion and (II) Carrier Overlapping Pulse Width Modulation (COPWM) which enhances the output voltage and higher DC bus utilization than non-overlapping PWM methods. The results also indicate that appropriate PWM strategies are to be employed depending on the performance measure required in a particular application of MLI based on the criteria of output voltage quality (peak value of the fundamental and dominant harmonic components).
\end{abstract}

\section{Keywords}

MLI, MSMI, Carrier based Pulse Width Modulation (PWM), sub harmonic PWM method, CFD, THD

\section{INTRODUCTION}

Recently, for high-performance power application, multilevel converters are widely used such as static- VAR compensators, motor drives and active power filters. For high-power applications, multilevel inverter structures have the particular advantages of operation at high DC bus voltages, achieved using series connections of switching devices and a reduction in output voltage harmonics achieved by switching between multiple voltage levels The advantages of multilevel inverters are good power quality, low switching losses and high voltage capability [1-2]. Multilevel topologies are classified into three categories: diode clamped inverters, flying capacitor inverters, and cascaded inverters [3]. A matrix of semiconductor switches and diodes allows each phase-leg output to be switched to any of these voltage levels. The cascaded inverter uses series strings of single phase full bridge inverters to construct multilevel phase legs [3-5]. A particular advantage of this topology is that the modulation, control and protection requirements of each bridge are modular. However, each single-phase inverter requires its own isolated DC supply, typically derived from a multiwinding low-frequency transformer or high-frequency DC-to-DC converters. This complexity has generally restricted cascaded inverters to the higher power range where several switched output voltage levels are needed and a diode-clamped structure is unsuitable because of the difficulty of balancing the series DC capacitor voltages. The most popular control technique for traditional inverters is the sinusoidal or "sub harmonic" natural pulse width modulation method. Its popularity is due to its simplicity and to the good results it guarantees in all the operating conditions [6-8]. Analysis and comparison of multicarrier PWM schemes applied in $\mathrm{H}$-bridge cascaded multilevel inverter are presented in [9-10]. The PWM techniques employed in inverters may be unipolar or bipolar type. Unipolar switching provides better quality output than bipolar switching[11]. Panda and Tripathi presented a symmetrical hybrid sine PWM switching technique for full bridge inverter. Hybrid PWM (HPWM) switching not only reduces overall switching loss but also reduces circuit complexity [12]. Shanthi and Natarajan presented a comparative study on various unipolar PWM strategies for single phase five level cascaded inverter [13]. Three kinds of novel PWM methods for multilevel inverter are analysed by Yang Deng et al [14]. These methods utilized vertical offsets among carriers as the control freedom degree. Analytical solutions for the most common forms of PWM such as constant switching frequency [15-18], control freedom degree [19] for cascaded multilevel inverter methodologies are used to identify modulation commonality between these methodologies. An improved modulation strategy for a hybrid MLI was developed by McGrath et al [20] and novel MLI carrier based PWM has been extensively discussed by Tolbert et al in [21]. Understanding gained from this comparison is then exploited in this paper to develop the harmonically superior modulation strategy which exhibits reduced harmonics and higher DC bus utilization for carrier overlapping and non-overlapping PWM methods. 


\section{MODULAR CASCADED H-BRIDGE CONFIGURATION AND ITS OPERATION}

There are several types of multilevel inverters but the one considered in this paper is the Modular Structured Multilevel Inverter (MSMI). The structure of the MSMI is not only simple and but also requires the least number of components compared to other types of multilevel inverters. This in turn, provides the flexibility in extending the MSMI to higher number of levels without undue increase in circuit complexity as well as facilitates packaging $[2,4,8]$.

\subsection{Single Phase Structure of a Modular}

Five Level Cascaded Multilevel Inverter

A single-phase structure of an m-level cascaded inverter is illustrated in Fig.1. Each Separate DC Source (SDCS) is connected to a single phase full bridge or H-bridge inverter. Each inverter level can generate three different voltage outputs, $+\mathrm{Vdc}, 0$, and $-\mathrm{Vdc}$ by connecting the DC source to the AC load by different combinations of the four switches as shown in Table 1. It denotes switching states of the upper and lower power devices of the two modules for MSMI. The AC load terminals of each of the different full bridge inverter modules are connected in series such that the synthesized output waveform resembles closely a sine wave. The number of output voltage levels $\mathrm{m}$ in a cascade inverter is defined by

$$
\mathrm{m}=2 \mathrm{M}+1
$$

where $\mathrm{M}$ is the number of separate DC sources required. The output voltage of chosen MSMI (Fig.1) is equal to the summation of the output voltages of the respective modules i.e.

$$
\mathrm{Vo}=\mathrm{V}_{\mathrm{a} 1}+\mathrm{V}_{\mathrm{a} 2}
$$

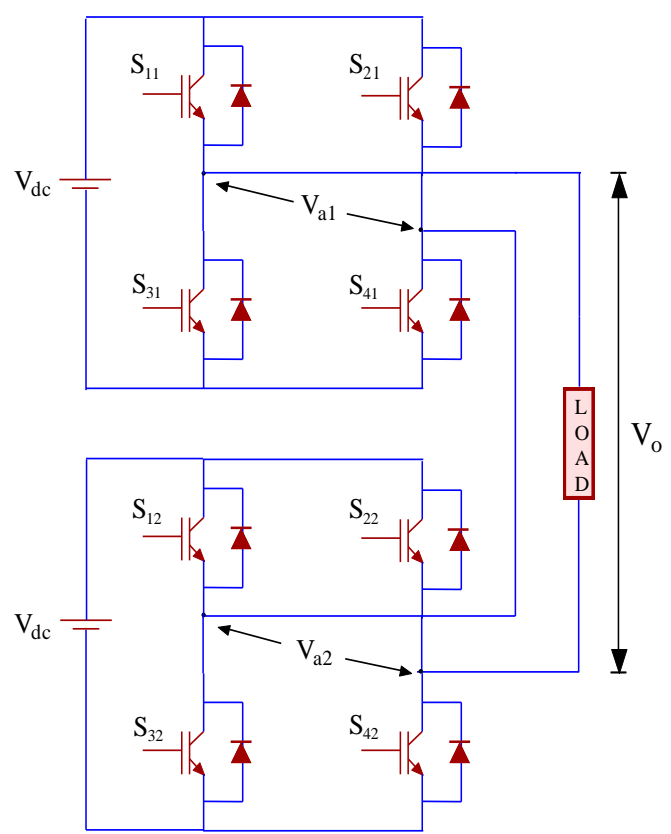

Figure 1: Power circuit for five-level inverter (MSMI)

where $\mathrm{V}_{\mathrm{a} 1}$ - output voltage of module 1 and $\mathrm{V}_{\mathrm{a} 2}$ - output voltage of module 2 [4,5]. A generalized quarter-wave symmetric stepped-voltage waveform synthesized by a $(2 \mathrm{M}+1)$ level inverter is shown in Fig. 2.

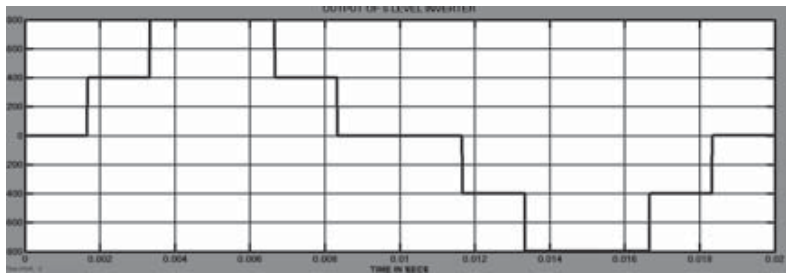

Figure 2: Generalized stepped voltage output waveform

Table 1. Switching strategy for five level MSMI

\begin{tabular}{|c|c|c|c|c|c|}
\hline \multirow{2}{*}{ Switches } & \multicolumn{5}{|c|}{ Load Voltage } \\
\cline { 2 - 6 } & $+2 V_{d c}$ & $+V_{d c}$ & 0 & $-V_{d c}$ & $-2 V_{d c}$ \\
\hline$S_{11}$ & ON & ON & ON & OFF & OFF \\
\hline$S_{21}$ & OFF & OFF & ON & ON & ON \\
\hline$S_{31}$ & OFF & OFF & OFF & ON & ON \\
\hline$S_{41}$ & ON & ON & OFF & OFF & OFF \\
\hline$S_{12}$ & ON & ON & ON & OFF & OFF \\
\hline$S_{22}$ & OFF & ON & ON & OFF & ON \\
\hline$S_{32}$ & OFF & OFF & OFF & ON & ON \\
\hline$S_{42}$ & ON & OFF & OFF & ON & OFF \\
\hline
\end{tabular}

\section{CONTROL AND MODULATION STRATEGIES}

The modulation methods used in multilevel inverters can be classified according to switching frequency as shown in Fig. 3 $[2,8]$.

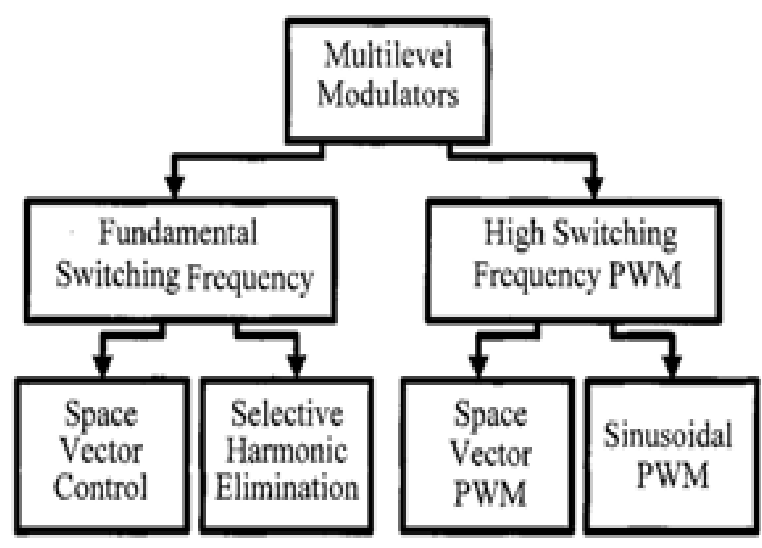

Figure 3: Classification of multilevel modulation methods

Methods that work with high switching frequencies have many commutations for the power semiconductors in one period of the fundamental output voltage. A very popular method in industrial applications is the classic carrier based sinusoidal PWM (SPWM) that uses the phase-shifting 
technique to reduce the harmonics in the load voltage. Methods that work with low switching frequencies generally perform one or two commutations of the power semiconductors during one cycle of the output voltage generating a staircase waveform.

\section{CARRIER BASED PWM METHODS}

The natural sampling techniques [6] for a multilevel inverter are categorized into two and they are:

Single Carrier SPWM (SCSPWM)

Multi Carrier PWM (MCPWM)

Multi Carrier PWM is an exclusive control strategy for multilevel inverters and has further classifications as discussed below. Several multicarrier techniques have been developed to reduce the distortion of outputs in multilevel inverters based on the classical SPWM [7, 8, 10, 11, 15, 16, $20,21]$ with triangular carriers.

The constant switching frequency pulse width modulation technique is most popular and is a very simple switching scheme. For m-level inverter, $\mathrm{m}-1$ carriers with the same frequency $\mathrm{f}_{\mathrm{c}}$ and the same amplitude $\mathrm{A}_{\mathrm{c}}$ are disposed such that the bands they occupy are contiguous. The reference waveform has peak-to-peak amplitude $A_{m}$, the frequency $f_{m}$ and it is zero centered in the middle of the carrier set. The reference is continuously compared with each of the carrier signals. If the reference is greater than a carrier signal, then the active device corresponding to that carrier is switched off. Carrier based PWM methods have more than one carrier that can be triangular waves or saw tooth waves and so on. As far as the particular carrier signals are concerned, there are multiple CFD including frequency, amplitude, phase of each carrier and offsets between carriers and as in three phase circuits, the injected zero sequence signal to the reference wave. Therefore multilevel carrier based PWM methods can have multiple CFD. These CFD combinations added with the basic topologies of MLIs will produce many multilevel carrier based PWM strategies.

The focus in this paper is on carrier based sinusoidal PWM schemes for controlling a cascaded multilevel inverter. In the sub-harmonic method, related to the way the adjustable amplitude carrier waves are placed in relation to the reference signal, four types of bipolar PWM strategies can be distinguished as discussed below. The reference is sinusoidal.

\section{A. Phase Disposition (PD) PWM}

In this method all the carriers above and below zero reference line are in same phase. If all the carriers are selected with the same phase, the method is known as Phase Disposition (PD) method. Carrier and reference wave arrangements are as shown in Fig. 4(A).

\section{B. Variable Amplitude Phase Disposition (VAPD) PWM}

In this method all the carriers have the same frequency and the adjustable amplitude (different or unequal amplitudes). All the carriers above and below zero reference line are in same phase. Carrier and reference wave arrangements are as shown in Fig. 4(B).

\section{Variable Amplitude Phase Opposition Disposition (VAPOD) PWM}

In this method all the carriers have the same frequency and the adjustable amplitude (different or unequal amplitudes). But all the carriers above the zero value reference are in phase among them but in opposition (180 degrees phase shifted) with those below. Carrier and reference wave arrangements are as shown in Fig 4(C).

\section{Variable Amplitude Alternative Phase Opposition Disposition (VAAPOD) PWM}

In this method all the carriers have the same frequency and the adjustable amplitude (different or unequal amplitudes). All the carriers are alternatively in position which is shown in Fig. 4(D). There is phase shift of $180^{\circ}$ between adjacent carriers. Carrier and reference wave arrangements are as shown in Fig. 4(D).

The amplitude modulation index $\mathrm{m}_{\mathrm{a}}$ is defined for above schemes as

$$
m_{a}=\frac{2 A_{m}}{\left(n-1 \nexists_{c}\right.}
$$

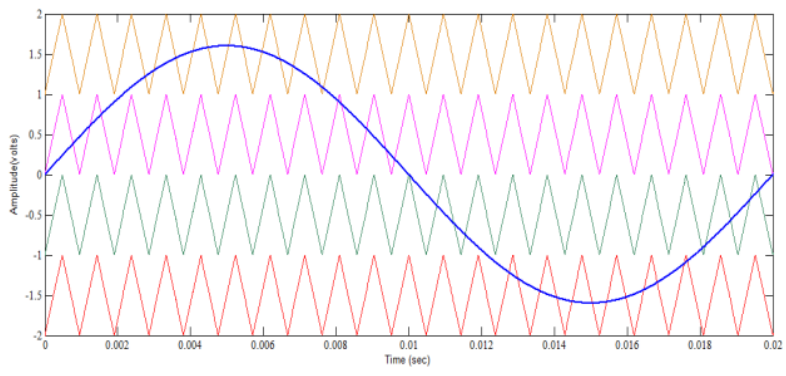

(A)

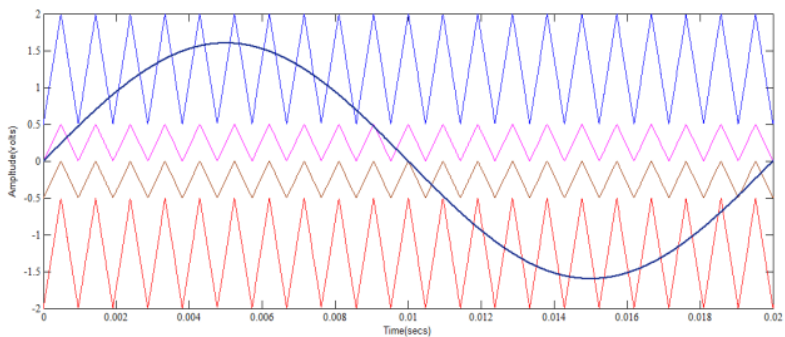

(B)

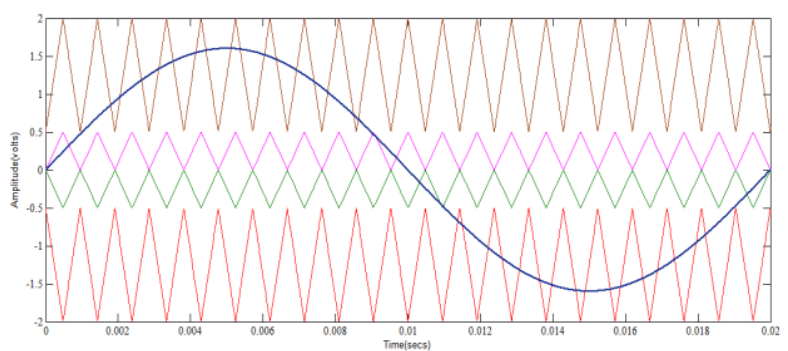

(C)

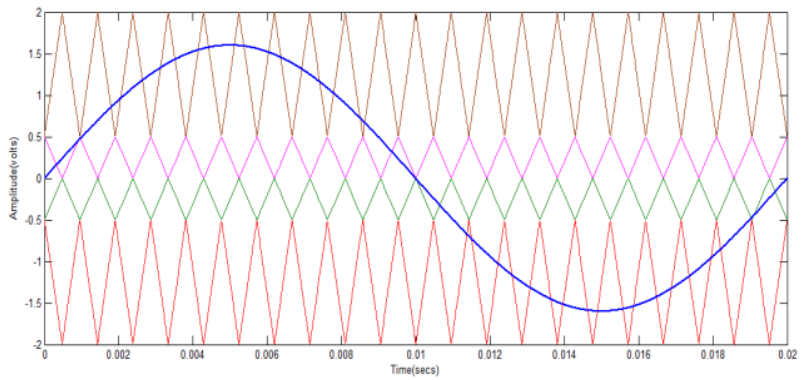

(D)

Figure 4: Constant switching frequency PWM carrier and reference wave arrangements

(A) PD PWM (B) VAPD PWM (C) VAPOD PWM (D) VAAPOD PWM 


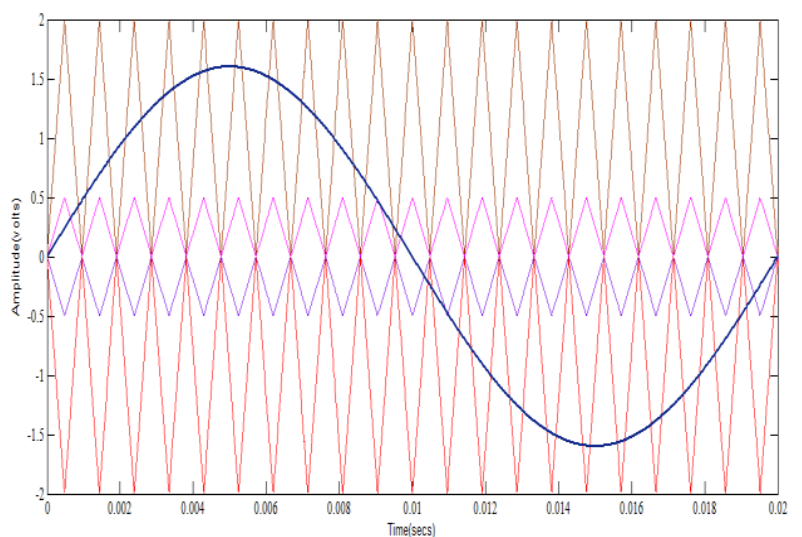

Figure 5: Carrier and reference wave arrangements for VACO PWM

\section{E. Variable Amplitude Carrier Overlapping (VACO) PWM}

The principle of COPWM is to use several overlapping carriers with single modulating signal. For an m-level inverter, $m-1$ carriers with the same frequency $f_{c}$ and same peak-to-peak amplitude $A_{c}$ are disposed such that the bands they occupy overlap each other. The overlapping vertical distance between each carrier is $A_{c} / 2$ in this work. The reference wave has the amplitude $A_{m}$ and frequency $f_{m}$ and it is centered in the middle of the carrier signals. The reference is continuously compared with each of the carrier Signals. If the reference is greater than carrier signal, then the active device corresponding to that carrier is switched off. The amplitude modulation index is given by

$$
m_{a}=\frac{A_{m}}{\left(\frac{m}{4}\right) A_{c}}
$$

In this work (Fig. 5), all carriers have the same frequency and the adjustable amplitude (different or unequal amplitudes).Four carriers are overlapped with each other and reference sine wave is placed at the middle of the four carriers. It can also be seen that they are divided equally into two groups according to the positive/negative average levels. In this strategy, two groups are opposite in phase with each other while keeping in phase within the group.

\section{SIMULATION RESULTS}

To validate the proposed generation of desired output voltage waveform, a prototype is simulated as shown in Fig. 6. The carriers are of adjustable amplitude and have same frequency. The gate signals are generated by comparing the reference wave with the carrier waves. In order to verify the operational behavior and examine the harmonic content of the MSMI applying carrier based sinusoidal PWM schemes, the circuit of Fig. 6. is simulated using MATLAB/SIMULINK power system block set for different modulation indices $\left(\mathrm{m}_{\mathrm{a}}=0.5-1\right)$ and for all the PWM techniques.

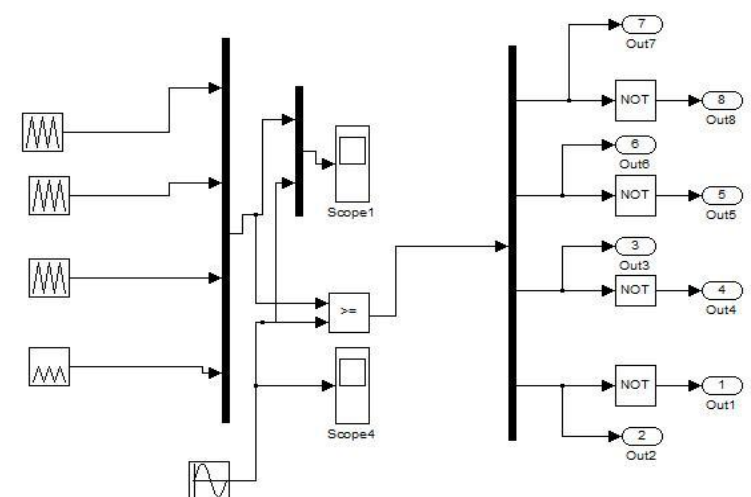

Figure 6: SIMULINK diagram/model of MSMI

The following parameter values are used for simulation: $\mathrm{Vdc}$ $=100 \mathrm{~V}$ and $\mathrm{R}$ (load) $=100$ ohms, $\mathrm{f}_{\mathrm{c}}=1050 \mathrm{~Hz}$ and $\mathrm{f}_{\mathrm{m}}=50$ Hz. The \% THD and variations of RMS (fundamental) output voltage for various PWM techniques for different modulation indices are as shown in Table 2 and Table 3.

Output voltage and their spectra are shown only for a moderate modulation index $\mathrm{m}_{\mathrm{a}}=0.8$ of chosen MSMI with various PWM schemes as in Figs. 7(a) - 11(b). Graphical comparison of the harmonic spectra and variations of RMS values are as shown in Figs. 12- 13.

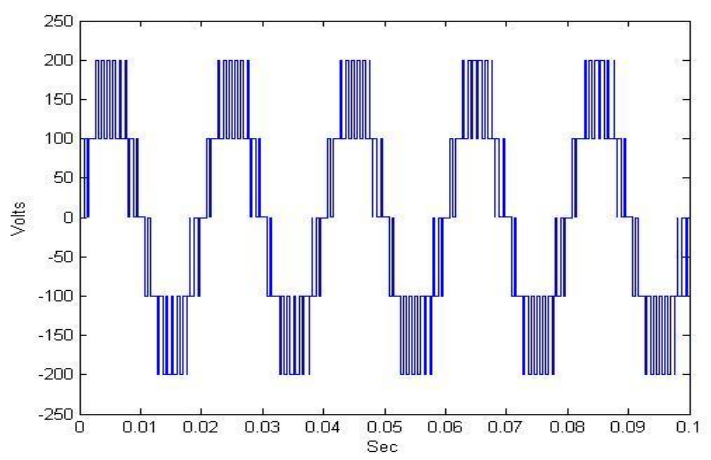

Figure 7(a): Output voltage using PD PWM

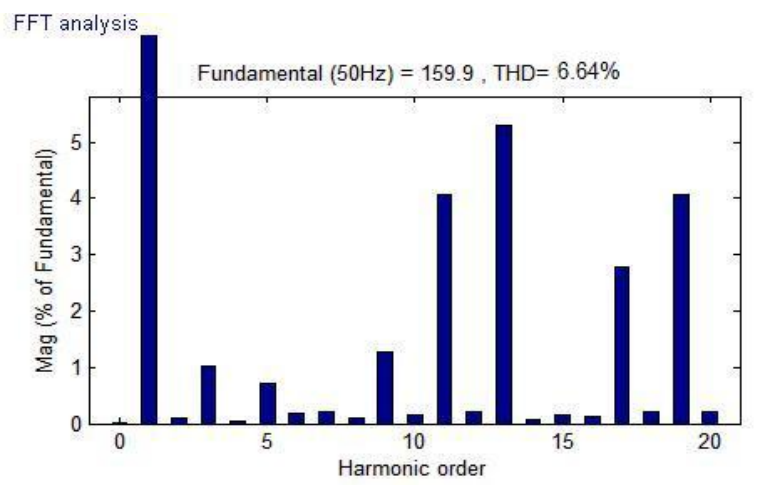

Figure 7(b): Output voltage spectrum using PD PWM 


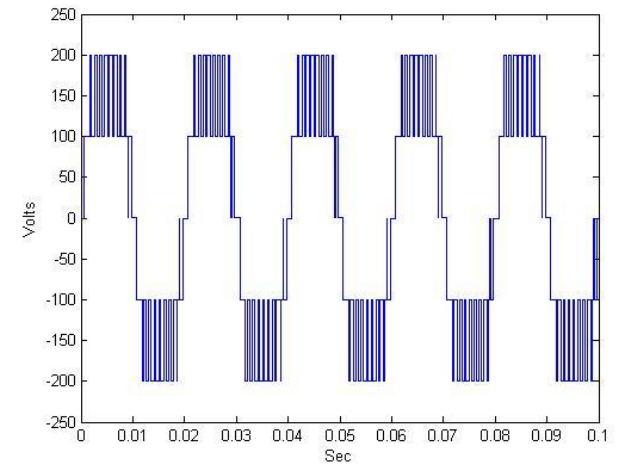

Figure 8(a): Output voltage using VAPD PWM

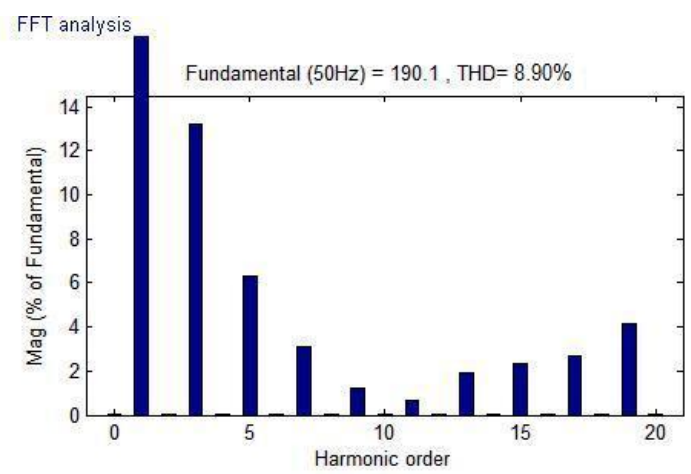

Figure 8(b): Output voltage spectrum using VAPD PWM

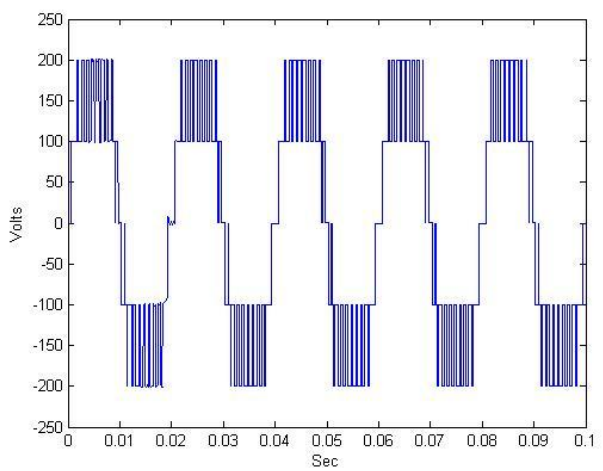

Figure 9(a): Output voltage using VAPOD PWM

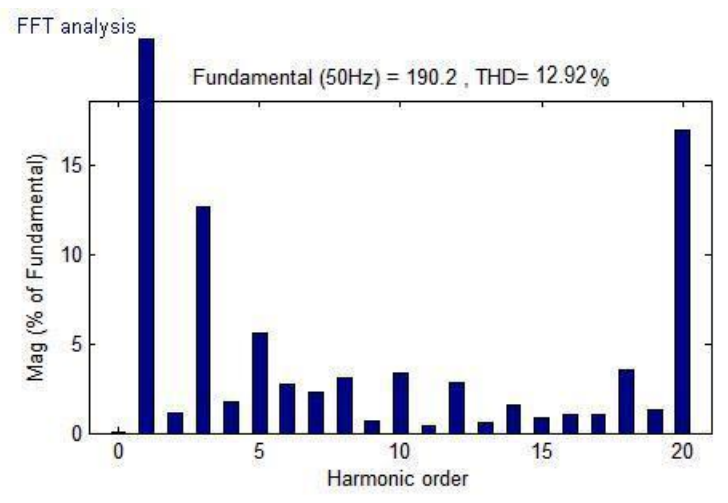

Figure 9(b): Output voltage spectrum using VAPOD PWM

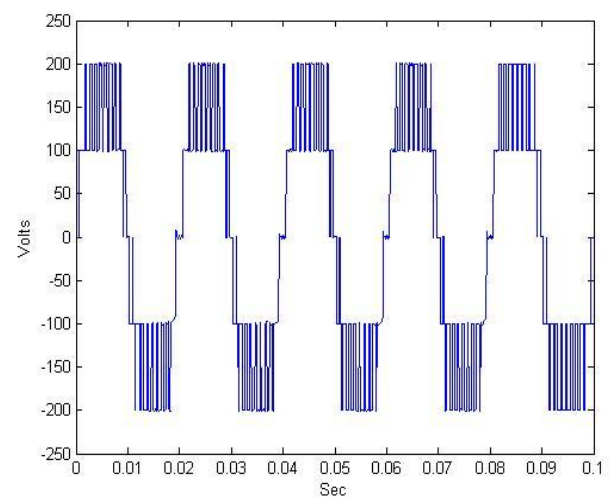

Figure 10(a): Output voltage using VAAPOD PWM

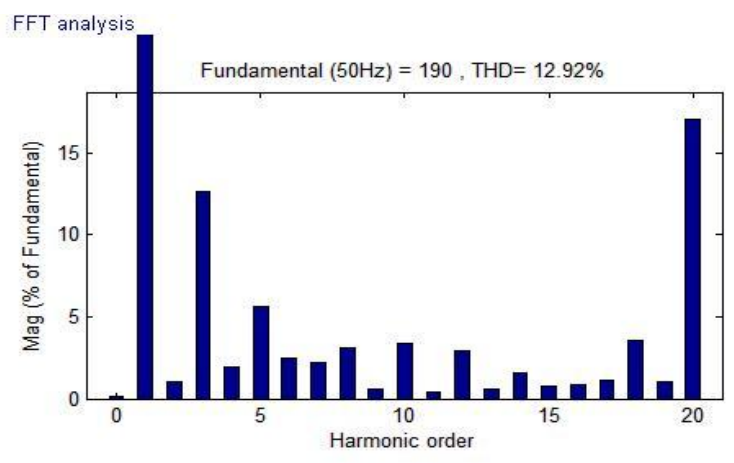

Figure 10(b): Output voltage spectrum using VAAPOD PWM

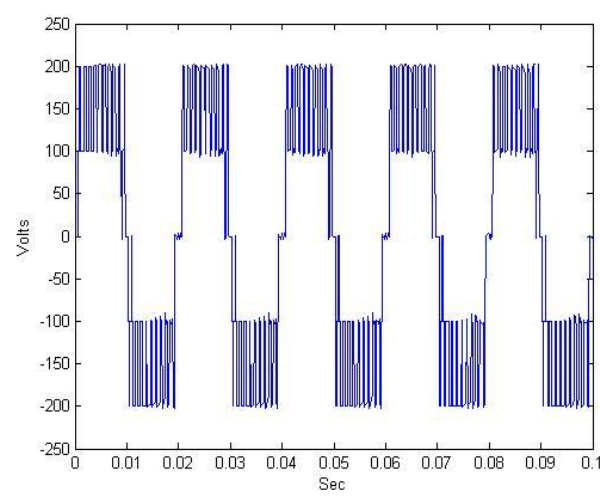

Figure 11(a): Output voltage using VACO PWM

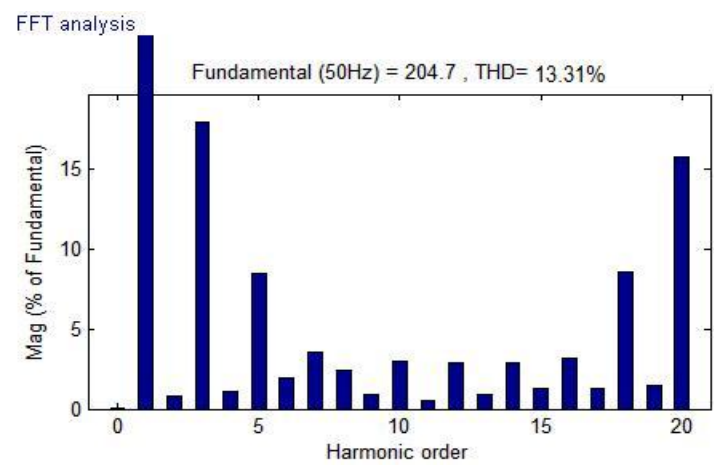

Figure 11(b): Output voltage spectrum using VACO PWM 
From the Table 2 and Fig, 12, it can be seen that PD PWM is the generally accepted method as it gives rise to the lowest harmonic distortion for higher modulation indices when compared to other methods.

VAPD PWM method gives rise to better THD for lower and moderate modulation indices. It should be noted that VAPOD PWM and VAAPOD PWM method give almost the same results from the viewpoint of harmonic performances for all modulation indices.

From the Table 3 and Fig. 13 , it is found that VACOL PWM method provides higher DC bus utilisation.

THD vs Modulation Index

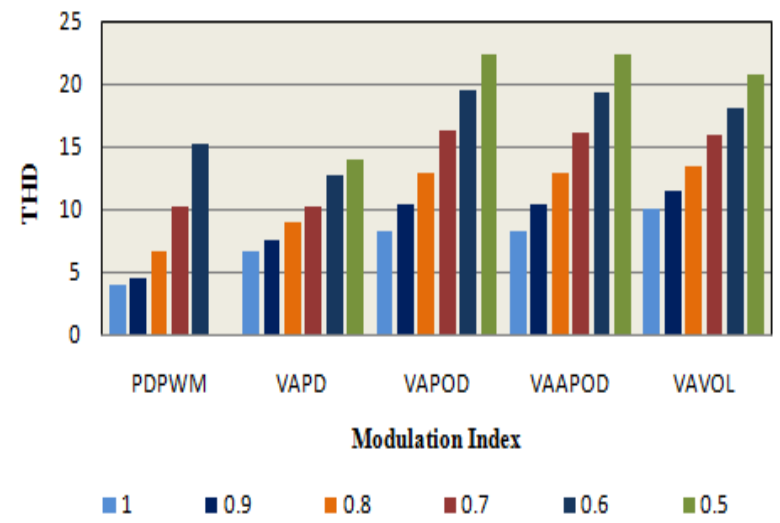

Figure 12: Harmonic spectra for various PWM for different $m_{a}$

Table 2. COMPARISON OF SIMULATED THD FOR DIFFERENT MODULATION INDICES WITH VARIOUS PWM SCHEMES

\begin{tabular}{|c|c|c|c|c|c|}
\hline $\mathbf{m}_{\mathbf{a}}$ & PDPWM & VAPD & VAPOD & VAAPOD & VACO \\
\hline $\mathbf{1 . 0}$ & 3.86 & 6.56 & 8.13 & 8.27 & 9.92 \\
\hline $\mathbf{0 . 9}$ & 4.55 & 7.58 & 10.31 & 10.27 & 11.36 \\
\hline $\mathbf{0 . 8}$ & 6.64 & 8.90 & 12.92 & 12.92 & 13.31 \\
\hline $\mathbf{0 . 7}$ & 10.09 & 10.24 & 16.25 & 16.14 & 15.85 \\
\hline $\mathbf{0 . 6}$ & 15.25 & 12.72 & 19.40 & 19.33 & 18.05 \\
\hline $\mathbf{0 . 5}$ & - & 13.91 & 22.39 & 22.41 & 20.78 \\
\hline
\end{tabular}

Table 3. COMPARISON OF SIMULATED $\mathrm{V}_{\text {RMS }}$ FOR DIFFERENT MODULATION INDICES WITH VARIOUS PWM SCHEMES

\begin{tabular}{|c|c|c|c|c|c|}
\hline $\mathbf{m}_{\mathbf{a}}$ & PDPWM & VAPD & VAPOD & VAAPOD & VACO \\
\hline $\mathbf{1 . 0}$ & 141.5 & 153.7 & 153.6 & 153.5 & 159.1 \\
\hline $\mathbf{0 . 9}$ & 127.2 & 144.3 & 144.2 & 144.5 & 152.6 \\
\hline $\mathbf{0 . 8}$ & 113.1 & 134.4 & 134.5 & 134.3 & 144.8 \\
\hline $\mathbf{0 . 7}$ & 98.94 & 124.6 & 124.5 & 124.7 & 136.3 \\
\hline $\mathbf{0 . 6}$ & 84.8 & 114.7 & 114.9 & 114.9 & 129.6 \\
\hline $\mathbf{0 . 5}$ & - & 104.5 & 104.1 & 104 & 121.4 \\
\hline
\end{tabular}




\section{CONCLUSION}

In this paper, PWM schemes adopting the constant switching frequency multicarrier, CFD concepts are implemented. Performance factors like \% THD and $\mathrm{V}_{\mathrm{RMS}}$ (indicating the amount of DC bus utilization) related to power quality issues have been evaluated, presented and analysed. THD of output voltage is minimum in PD PWM for higher modulation indices. To get the increased RMS output voltage, the VACO PWM technique is most suitable. VAPD PWM gives rise to lower THD for lower and moderate modulation indices. The results also indicate that appropriate PWM strategies can be employed depending on the performance measure required in a particular application of MLI based on the criteria of output voltage quality (peak value of the fundamental and dominant harmonic components).

\section{REFERENCES}

[1] J. S. Lai and F. Z. Peng, 'Multilevel converters-A new breed of power converters', IEEE Trans. Ind. Applicat., Vol. 32, pp. 509-517, May/June 1996.

[2] José Rodríguez, Jih-Sheng Lai and Fang Zheng Peng, 'Multilevel Inverters: A Survey of Topologies, Controls, and Applications', IEEE Transactions on Industrial Electronics, Vol. 49, No. 4, August 2002.

[3] Surin Khomfoi and Leon M. Tolbert, 'Multilevel power converters', Power Electronics Handbook, 2nd ed., Elsevier Publishers, 2006.

[4] K.A.Corzine and Y.L Familiant,. 'A new cascaded multilevel H-bridge drive', IEEE Trans. Power Electron., Vol. 17, pp. 125-131, 2002.

[5] R.Teodorescu, F.Blaabjerg, J.K.Pedersen, J.K., E.Cengelci, P.N.Enjeti, 'Multilevel inverter by cascading industrial VSI', IEEE Trans. Ind.Electron., Vol.49, pp. 832-838,2002.

[6] G.Carrara, S.Gardella, M.Marchesoni, R.Salutari and G.Sciutto, 'A new multilevel PWM method: A theoretical analysis', IEEE Trans. on Power Electron., Vol.7, pp. 497-505, July 1992.

[7] M.S.Bakar and N.A.Azli, 'Simulation of a regular sampled pulse width modulation technique for a multilevel inverter', in IEEE National Power and Energy Conference (PECon) 2003 Conf. Rec.: 0-7803-82030/03, 2003, pp.144-147.

[8] N.Mohan, T.M.Undeland and W.P.Robbins, Power Electronics; Converter, Applications and Design. John Wiley \& Son, pp. 211-218,2003.

[9] Martina Calais, Lawrence J. Borle and Vassilios G. Agelidis., 'Analysis of multicarrier PWM methods for a single phase five level inverter', in IEEE Conf. Rec.: 07803-7067-8/01, 2001, pp.1351-1356.

[10] Tengfei Wang and Yongqiang Zhu, 'Analysis and comparision of multicarrier PWM schemes applied in $\mathrm{H}-$ bridge cascaded multilevel Inverter', in $5^{\text {th }}$ IEEE Conf. on Indutrial Electronics and Applications, 2010, pp.1379-1383.

[11] Xiumei Yue, Xuejun Ma and Hongliang Wang, 'A concept of unipolar $\mathrm{N}$-multiple frequency SPWM and the main circuit topology', in IEEE Power Electronic and Motion Control Conference, IPEMC'09, 2009, pp.15311534.

[12] R.Panda and R.K.Tripathi, 'A symmetrical hybrid sine PWM switching technique for full bridge inverters', in India International Conference on Power Electronics, 2006, 345-348.

[13] B.Shanthi and S.P.Natarajan, 'Comparative study on various unipolar PWM strategies for single phase five level cascaded inverter', International Journal of Power Electronics (IJPELEC), Special issue on: Power Converters:Modeling, Simulation, Analysis, Topologies, Secondary issues and Applications, InderScience Pubilication,Switzerland, pp.36-50, 2009.

[14] Y.Deng, H.Wang, C.Zhang, L.Hu and X.He, 'Multilevel PWM methods based on control degrees of freedom combination and its theoretical analysis', IEEE Industry Applications Conference, 2005. Fortieth IAS Annual Meeting. Conference Record of the 2005, Vol.3, 1692 1699,2005 .

[15] B.P.McGrath and D.G.Holmes, 'Multicarrier PWM strategies for multilevel inverter', IEEE Trans. on Ind. Electron., Vol.49, pp. 858-867,2002.

[16] B.P.McGrath, D.G.Holmes and T.Meynard, 'Reduced PWM harmonic distortion for multilevel inverter operating over a wide modulation range', IEEE Trans. on Power Electron., Vol. 21, pp. 941-949,2006.

[17] P.Palanivel and S.S.Dash, ' Analysis of THD and output voltage performance for cascaded multilevel inverter using carrier pulse width modulation techniques', IET Power Electron., Vol. 4, pp. 951-958,2011.

[18] S.Sirisukpraserl, J.S.Lai and T.H.Liu, 'Optimum harmonic reduction with a wide range of modulation indices for multilevel converters', IEEE Trans. Ind. Electron., Vol.49, pp. 875-881,2002.

[19] B.Shanthi and S.P.Natarajan, 'Carrier overlapping PWM methods for single phase cascaded five level inverter', International Journal of Science and Techniques of Automatic Control \& Computer Engineering (IJ-STA, Tunisia), Special issue on Control of Electrical Machines,pp. 590-601, December 2008.

[20] B. P. McGrath, D. G. Holmes, M. Manjrekar, and T. A. Lipo, 'Improved modulation strategy for a hybrid multilevel inverter', in Conf. Rec. IEEE-IAS Annu. Meeting, 2000, pp. 2086-2093.

[21] L.M.Tolber and T.G.Habetler, 'Novel multilevel inverter carrier based PWM method', IEEE Trans. Ind. Appl., Vol.35, pp. 1098-1107,1999. 